\title{
On Multivalued Contractions in Cone Metric Spaces without Normality
}

\author{
Muhammad Arshad ${ }^{1}$ and Jamshaid Ahmad ${ }^{2}$ \\ ${ }^{1}$ Department of Mathematics, International Islamic University, H-10, Islamabad 44000, Pakistan \\ ${ }^{2}$ Department of Mathematics, COMSATS Institute of Information Technology, Chak Shahzad, Islamabad 44000, Pakistan
}

Correspondence should be addressed to Jamshaid Ahmad; jamshaid_jasim@yahoo.com

Received 4 April 2013; Accepted 15 May 2013

Academic Editors: A. Agouzal, A. Ibeas, F. Khani, and F. Kittaneh

Copyright (c) 2013 M. Arshad and J. Ahmad. This is an open access article distributed under the Creative Commons Attribution License, which permits unrestricted use, distribution, and reproduction in any medium, provided the original work is properly cited.

\begin{abstract}
Wardowski (2011) in this paper for a normal cone metric space $(X, d)$ and for the family $\mathscr{A}$ of subsets of $X$ established a new cone metric $H: \mathscr{A} \times \mathscr{A} \rightarrow E$ and obtained fixed point of set-valued contraction of Nadler type. Further, it is noticed in the work of Janković et al., 2011 that the fixed-point problem in the setting of cone metric spaces is appropriate only in the case when the underlying cone is nonnormal. In the present paper we improve Wardowski's result by proving the same without the assumption of normality on cones.
\end{abstract}

\section{Introduction and Preliminaries}

Huang and Zhang [1] generalized the notion of metric space by replacing the set of real numbers by ordered Banach space and defined cone metric space and extended Banach type fixed-point theorems for contractive type mappings. Subsequently, some other authors (e.g., see [2-15] and references therein) studied properties of cone metric spaces and fixed points results of mappings satisfying contractive type condition in cone metric spaces. Recently, Choa et al. [9], Kadelburg and Radenović [16], Klim and Wardowski [17], Latif and Shaddad [18], Radenović and Kadelburg [19], Rezapour and Haghi [20], and Wardowski [14, 21] obtained fixed points of set-valued mappings in normal cone metric spaces. On the other hand, it is shown in [11] that most of the fixed points results of mappings satisfying contractive type condition in cone metric spaces with a normal cone can be reduced to the corresponding results from metric space theory. The fixed-point problem in the setting of cone metric spaces is appropriate only in the case when the underlying cone is nonnormal, because the results concerning fixed points and other results in the case of cone metric spaces with nonnormal solid cones cannot be proved by reducing to metric spaces. In this paper, we prove the result of Wardowski
[14] without the assumption of normality of cones. We need the following definitions and results, consistent with $[1,11,14]$.

Let $E$ be a Banach Space and $P$ a subset of $E$. Then, $P$ is called a cone whenever

(i) $P$ is closed, nonempty, and $P \neq\{\theta\}$,

(ii) $a x+b y \in P$ for all $x, y \in P$ and nonnegative real numbers $a, b$,

(iii) $P \cap(-P)=\{\theta\}$.

Each cone $P$ induces a partial ordering $\preccurlyeq$ on $E$ by $x \leqslant y$ if and only if $y-x \in P$. So $x<y$ will stand for $x \leqslant y$ and $x \neq y$, while $x \ll y$ will stand for $y-x \in \operatorname{int} P$, where int $P$ denotes the interior of $P$. The cone $P$ is called normal if there is a number $K>0$ such that, for all $x, y \in E$,

$$
\theta \preccurlyeq x \preccurlyeq y \Longrightarrow\|x\| \leq K\|y\| \text {. }
$$

The least positive number $K$ satisfying (1) is called the normal constant of $P$.

Definition 1. Let $X$ be a nonempty set. Suppose the mapping $d: X \times X \rightarrow E$ satisfies $\left(\mathrm{d}_{1}\right) \theta \preccurlyeq d(x, y)$ for all $x, y \in X$ and $d(x, y)=\theta$ if and only
if $x=y$, 
$\left(\mathrm{d}_{2}\right) d(x, y)=d(y, x)$ for all $x, y \in X$,

$\left(\mathrm{d}_{3}\right) d(x, y) \leqslant d(x, z)+d(z, y)$ for all $x, y, z \in X$.

Then, $d$ is called a cone metric on $X$, and $(X, d)$ is called a cone metric space.

Let $(X, d)$ be a cone metric space, $x \in X$ and $\left\{x_{n}\right\}_{n \geq 1}$ a sequence in $X$. Then, $\left\{x_{n}\right\}_{n \geq 1}$ converges to $x$ whenever for every $c \in E$ with $\theta \ll c$ there is a natural number $N$ such that $d\left(x_{n}, x\right) \ll c$ for all $n \geq N$. We denote this by $\lim _{n \rightarrow \infty} x_{n}=x$ or $x_{n} \rightarrow x \cdot\left\{x_{n}\right\}_{n \geq 1}$ is a Cauchy sequence whenever for every $c \in E$ with $\theta \ll c$ there is a natural number $N$ such that $d\left(x_{n}, x_{m}\right) \ll c$ for all $n, m \geq N$. $(X, d)$ is called a complete cone metric space if every Cauchy sequence in $X$ is convergent.

A set $A \subset(X, d)$ is called closed if, for any sequence $\left\{x_{n}\right\} \subset A$ convergent to $x$, we have $x \in A$. Denote by $N(X)$ the collection of all nonempty subsets of $X$ and by $C(X)$ a collection of all nonempty closed subsets of $X$. Denote by Fix $T$ a set of all fixed points of a mapping $T$. In the present paper, we assume that $E$ is a real Banach space, $P$ is a cone in $E$ with nonempty interior (such cones are called solid), and $\preccurlyeq$ is a partial ordering with respect to $P$. In accordance with [14, Definition 3.1 and Lemma 3.1], we minutely modify the idea of $\mathrm{H}$-cone metric to make it more comparable with a standard metric.

Definition 2. Let $(X, d)$ be a cone metric space and $\mathscr{A}$ be a collection of nonempty subsets of $X$. A map $H: \mathscr{A} \times$ $\mathscr{A} \rightarrow E$ is called an $H$-cone metric on $\mathscr{A}$ induced by $d$ if the following conditions hold:

$\left(\mathrm{H}_{1}\right) \theta \preccurlyeq H(A, B)$ for all $A, B \in \mathscr{A}$ and $H(A, B)=\theta$ if and only if $A=B$,

$\left(\mathrm{H}_{2}\right) H(A, B)=H(B, A)$ for all $A, B \in \mathscr{A}$,

$\left(\mathrm{H}_{3}\right) H(A, B) \preccurlyeq H(A, C)+H(C, B)$ for all $A, B, C \in \mathscr{A}$,

$\left(\mathrm{H}_{4}\right)$ If $A, B \in \mathscr{A}, \theta \prec \varepsilon \in E$ with $H(A, B) \prec \varepsilon$, then for each $a \in A$ there exists $b \in B$ such that $d(a, b) \prec \varepsilon$.

Examples can be seen in [14, examples 3.1 and 3.2].

\section{Main Result}

Theorem 3. Let $(X, d)$ be a complete cone metric space. Let $\mathscr{A}$ be a nonempty collection of nonempty closed subsets of $X$, and let $H: \mathscr{A} \times \mathscr{A} \rightarrow E$ be an $H$-cone metric induced by $d$. If for a map $T: X \rightarrow \mathscr{A}$ there exists $\lambda \in(0,1)$ such that for all $x, y \in X$

$$
H(T x, T y) \preccurlyeq \lambda d(x, y),
$$

then $\operatorname{Fix} T \neq \emptyset$.

Proof. Let $x_{0}$ be an arbitrary but fixed element of $X$ and $x_{1} \in$ $T x_{0}$. If $x_{0}=x_{1}$, then $x_{0} \in$ Fix $T$, and if $x_{0} \neq x_{1}$, using the fact that

$$
H\left(T x_{0}, T x_{1}\right) \preccurlyeq \lambda d\left(x_{0}, x_{1}\right) \prec \sqrt{\lambda} d\left(x_{0}, x_{1}\right)
$$

we may choose $x_{2} \in X$ such that $x_{2} \in T x_{1}$ and

$$
d\left(x_{1}, x_{2}\right) \prec \sqrt{\lambda} d\left(x_{0}, x_{1}\right) .
$$

Similarly, in case $x_{1} \neq x_{2}$, we may choose $x_{3} \in X$ such that $x_{3} \in T x_{2}$ and

$$
d\left(x_{2}, x_{3}\right) \prec \sqrt{\lambda} d\left(x_{1}, x_{2}\right) \prec(\sqrt{\lambda})^{2} d\left(x_{0}, x_{1}\right) .
$$

We can continue this process to find a sequence $\left\{x_{n}\right\}$ of points of $X$ such that

$$
\begin{gathered}
x_{n+1} \in T x_{n}, \quad n=0,1,2, \ldots, \\
d\left(x_{n}, x_{n+1}\right) \prec \sqrt{\lambda} d\left(x_{n-1}, x_{n}\right) \\
\prec(\sqrt{\lambda})^{2} d\left(x_{n-2}, x_{n-1}\right) \prec \cdots \prec(\sqrt{\lambda})^{n} d\left(x_{0}, x_{1}\right) .
\end{gathered}
$$

Now for any $m>n$,

$$
\begin{aligned}
d\left(x_{m}, x_{n}\right) & \preccurlyeq d\left(x_{n}, x_{n+1}\right)+d\left(x_{n+1}, x_{n+2}\right)+\cdots+d\left(x_{m-1}, x_{m}\right) \\
& \preccurlyeq\left[\lambda^{n / 2}+\lambda^{(n+1) / 2}+\cdots+\lambda^{(m-1) / 2}\right] d\left(x_{0}, x_{1}\right) \\
& \preccurlyeq\left[\frac{\lambda^{n / 2}}{1-\lambda^{1 / 2}}\right] d\left(x_{0}, x_{1}\right) .
\end{aligned}
$$

Let $\theta \ll c$ be given. Choose a symmetric neighborhood $V$ of $\theta$ such that $c+V \subseteq$ int $P$. Also, choose a natural number $N_{1}$ such that $\left[\lambda^{n / 2} /\left(1-\lambda^{1 / 2}\right)\right] d\left(x_{0}, x_{1}\right) \in V$, for all $n \geq N_{1}$. Then, $\left(\lambda^{n / 2} /\left(1-\lambda^{1 / 2}\right)\right) d\left(x_{1}, x_{0}\right) \ll c$, for all $n \geq N_{1}$. Thus,

$$
d\left(x_{m}, x_{n}\right) \preccurlyeq\left[\frac{\lambda^{n / 2}}{1-\lambda^{1 / 2}}\right] d\left(x_{0}, x_{1}\right) \ll c,
$$

for all $m>n$. Therefore, $\left\{x_{n}\right\}_{n \geq 1}$ is a Cauchy sequence. Since $X$ is complete, there exists $u \in X$ such that $x_{n} \rightarrow u$. Since

$$
H\left(T x_{n}, T u\right) \preccurlyeq \lambda d\left(x_{n}, u\right) \prec \sqrt{\lambda} d\left(x_{n}, u\right),
$$

for each $n, x_{n+1} \in T x_{n}$, we have $y_{n} \in T u$ such that $d\left(x_{n+1}, y_{n}\right) \prec \sqrt{\lambda} d\left(x_{n}, u\right)$. Now, choose a natural number $\mathrm{N}_{2}$ such that

$$
d\left(x_{n}, u\right) \ll \frac{c}{2} \quad \forall n \geq N_{2}
$$

Then for all $n \geq N_{2}$,

$$
\begin{aligned}
d\left(u, y_{n}\right) & \preccurlyeq d\left(u, x_{n+1}\right)+d\left(x_{n+1}, y_{n}\right) \\
& \preccurlyeq d\left(u, x_{n+1}\right)+\sqrt{\lambda} d\left(x_{n}, u\right) \\
& \leqslant d\left(u, x_{n+1}\right)+d\left(x_{n}, u\right) \ll \frac{c}{2}+\frac{c}{2}=c .
\end{aligned}
$$

It follows that $y_{n} \rightarrow u$, and it implies that $u \in T u$. 
Example 4. Suppose $X=[0,1], E=C_{R}^{2}[0,1]$ with the norm $\|x\|=\|x\|_{\infty}+\left\|x^{\prime}\right\|_{\infty}, P=\{x \in E: x \geq 0\}, x(t)=t$, and $y(t)=t^{2 K}$. Then, $0 \leq x \leq y,\|x\|=2$, and $\|y\|=1+2 K$. For all $K \geq 1$, since $K\|x\|<\|y\|$. Therefore, $P$ is non-normal. Define $d: X \times X \rightarrow E$ as follows:

$$
(d(x, y))(t)=|x-y| e^{t}
$$

Let $\mathscr{A}$ be a family of subsets of $X$ of the form $\mathscr{A}=\{[0, x]: x \in$ $X\} \cup\{\{x\}: x \in X\}$, and define $H: \mathscr{A} \times \mathscr{A} \rightarrow E$ as follows:

$$
\begin{aligned}
& H(A, B) \\
&= \begin{cases}|x-y| e^{t} & \text { for } A=[0, x], B=[0, y], \\
|x-y| e^{t} & \text { for } A=\{x\}, B=\{y\}, \\
\operatorname{Max}\{y,|x-y|\} e^{t} & \text { for } A=[0, x], B=\{y\}, \\
\operatorname{Max}\{x,|x-y|\} e^{t} & \text { for } A=\{x\}, B=[0, y] .\end{cases}
\end{aligned}
$$

It is easy to observe that $H$ satisfies $\left(\mathrm{H}_{1}\right)-\left(\mathrm{H}_{4}\right)$ of Definition 2. Define $T: X \rightarrow \mathscr{A}$ as

$$
T x= \begin{cases}\{0\}, & \text { for } x \in\left[0, \frac{1}{2}\right], \\ {\left[0, \frac{1}{2}\left(x-\frac{1}{2}\right)^{2}\right],} & \text { for } x \in\left(\frac{1}{2}, 1\right] .\end{cases}
$$

Note that $T$ satisfies the conditions of Theorem 3 with $\lambda=1 / 2$ and $0 \in$ Fix $T$.

\section{References}

[1] L.-G. Huang and X. Zhang, "Cone metric spaces and fixed point theorems of contractive mappings," Journal of Mathematical Analysis and Applications, vol. 332, no. 2, pp. 1468-1476, 2007.

[2] T. Abdeljawad, P. Murthy, and K. Tas, "A Gregus type common fixed point theorem of set-valued mappings in cone metric spaces," Journal of Computational Analysis and Applications, vol. 13, no. 4, pp. 622-628, 2011.

[3] J. Ahmad, M. Arshad, and C. Vetro, "On a theorem of khan in a generalized metric space," International Journal of Analysis, vol. 2013, Article ID 852727, 6 pages, 2013.

[4] M. Arshad, J. Ahmad, and E. Karapınar, "Some common fixed point results in rectangular metric spaces," Journal of Analysis, vol. 2013, Article ID 307234, 7 pages, 2013.

[5] A. G. Ahmad, Z. M. Fadail, M. Abbas, Z. Kadelburg, and S. Radenović, "Some fixed and periodic points in abstract metric spaces," Abstract and Applied Analysis, vol. 2012, Article ID 908423, 15 pages, 2012.

[6] M. Arshad, A. Azam, and P. Vetro, "Some common fixed point results in cone metric spaces," Fixed Point Theory and Applications, vol. 2009, Article ID 493965, 2009.

[7] S. H. Cho, J. S. Bae, and K. S. Na, "Fixed point theorems for multivalued contractive mappings and multivalued Caristi type mappings in cone metric spaces," Fixed Point Theory and Applications, vol. 2012, article 133, 10 pages, 2012.

[8] S. H. Cho and J. S. Bae, "Fixed point theorems for multivalued maps in cone metric spaces," Fixed Point Theory and Applications, vol. 2011, article 87, 2011.
[9] Y. J. Choa, S. Hirunworakit, and N. Petrot, "Set-valued fixedpoint theorems for generalized contractive mappings without the Hausdorff metric," Applied Mathematics Letters, vol. 24, no. 11, pp. 1959-1967, 2011.

[10] L. Gajić and V. Rakočević, "Qusai-contractions on a nonnormal cone metric space," Fund Analyzer Application, vol. 46, pp. 7579, 2012.

[11] S. Janković, Z. Kadelburg, and S. Radenović, "On cone metric spaces: a survey survey," Nonlinear Analysis. Theory, Methods \& Applications, vol. 74, pp. 2591-2601, 2011.

[12] G. Jungck, S. Radenović, S. Radojević, and V. Rakočević, "Common fixed point theorems for weakly compatible pairs on cone metric spaces," Fixed Point Theory and Applications, vol. 2009, Article ID 643840, 2009.

[13] S. R. Kumar, "Common fixed point theorems for sub compatible and sub sequentially continuous maps in 2 metric spaces," International MatheMatical Forum, vol. 7, no. 24, pp. 1187-1200, 2012.

[14] D. Wardowski, "On set-valued contractions of Nadler type in cone metric spaces," Applied Mathematics Letters, vol. 24, no. 3, pp. 275-278, 2011.

[15] Z. Kadelburg, S. Radenović, and V. Rakočević, "A note on the equivalence of some metric and cone metric fixed point results," Applied Mathematics Letters, vol. 24, pp. 370-374, 2011.

[16] Z. Kadelburg and S. Radenović, "Some results on set-valued contractions in abstract metric spaces," Computers and Mathematics with Applications, vol. 62, no. 1, pp. 342-350, 2011.

[17] D. Klim and D. Wardowski, "Dynamic processes and fixed points of set-valued nonlinear contractions in cone metric spaces," Nonlinear Analysis, Theory, Methods and Applications, vol. 71, no. 11, pp. 5170-5175, 2009.

[18] A. Latif and F. Y. Shaddad, "Fixed point results for multivalued maps in cone metric spaces," Fixed Point Theory and Applications, vol. 2010, article 87, Article ID 941371, 2010.

[19] S. Radenović and Z. Kadelburg, "Some results on fixed points of multifunctions on abstract metric spaces," Mathematical and Computer Modelling, vol. 53, no. 5-6, pp. 746-754, 2011.

[20] Sh. Rezapour and R. H. Haghi, "Fixed point of multifunctions on cone metric spaces," Numerical Functional Analysis and Optimization, vol. 30, no. 7-8, pp. 1-8, 2009.

[21] D. Wardowski, "Endpoints and fixed points of set-valued contractions in cone metric spaces," Nonlinear Analysis, Theory, Methods and Applications, vol. 71, no. 1-2, pp. 512-516, 2009. 


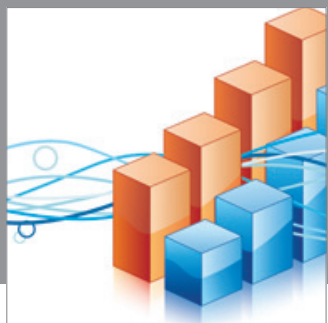

Advances in

Operations Research

mansans

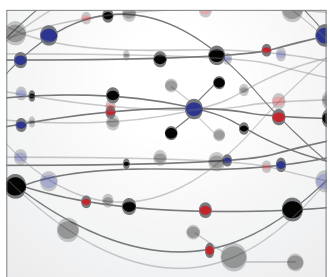

The Scientific World Journal
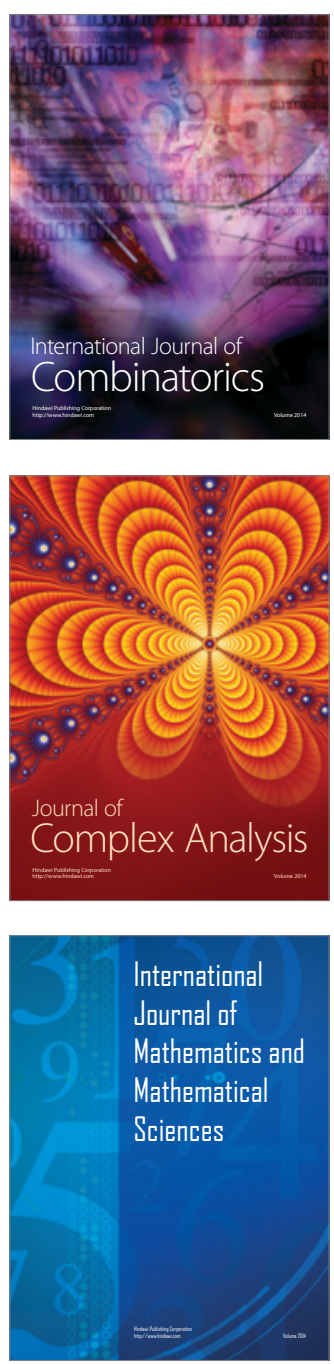
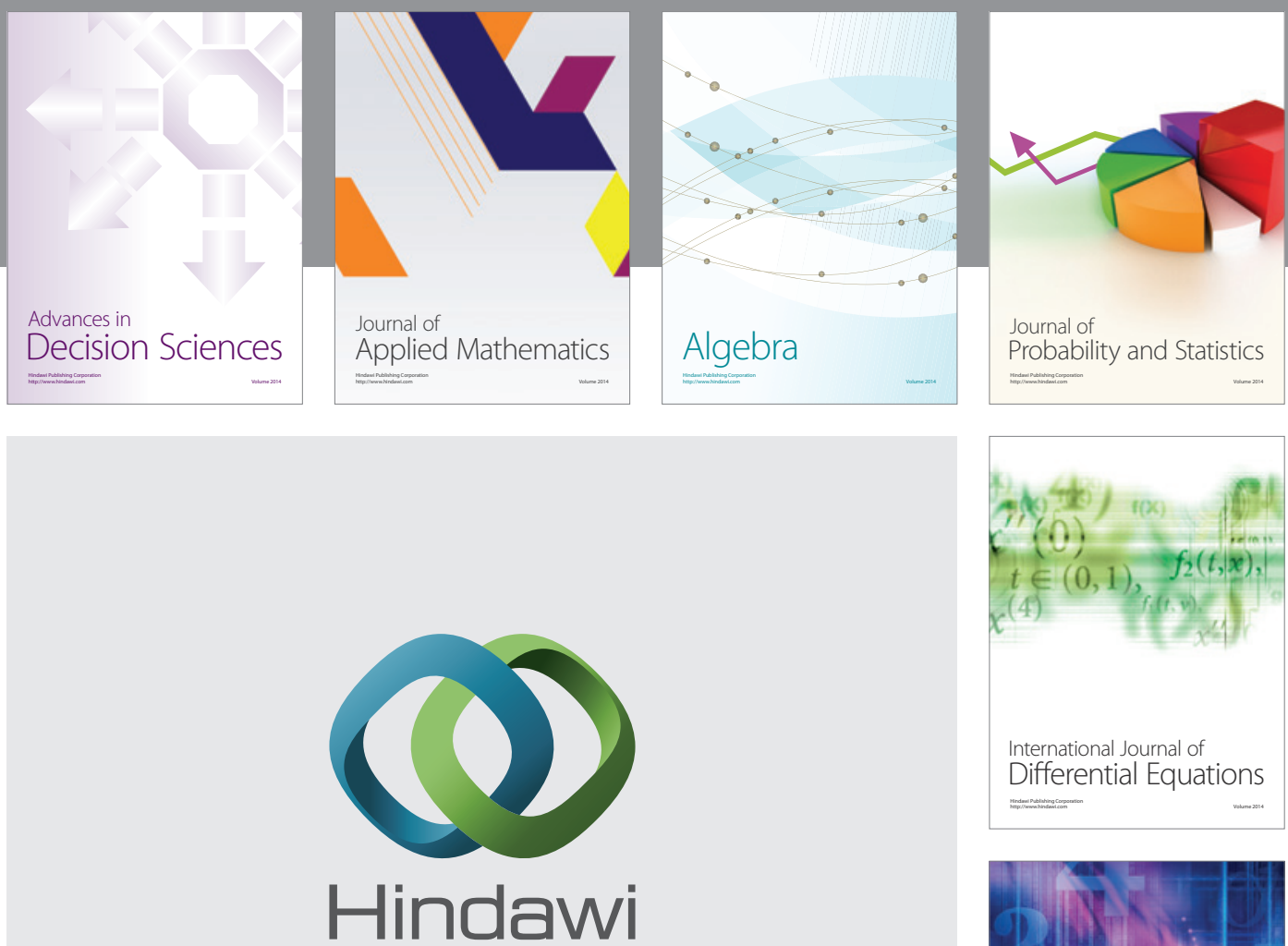

Submit your manuscripts at http://www.hindawi.com
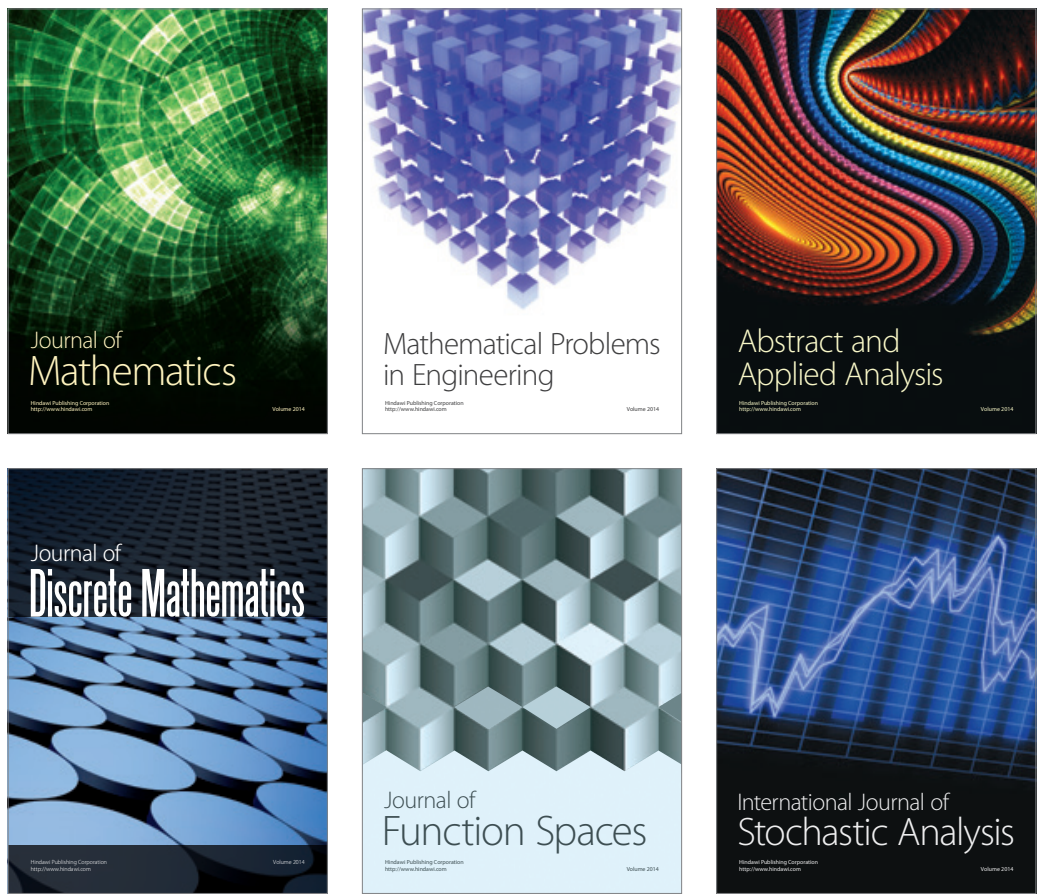

Journal of

Function Spaces

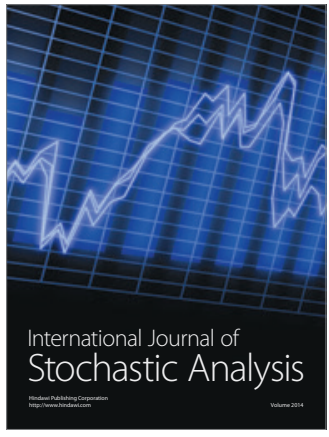

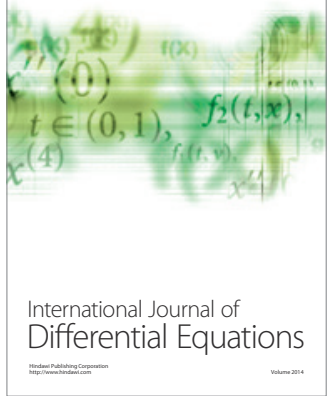
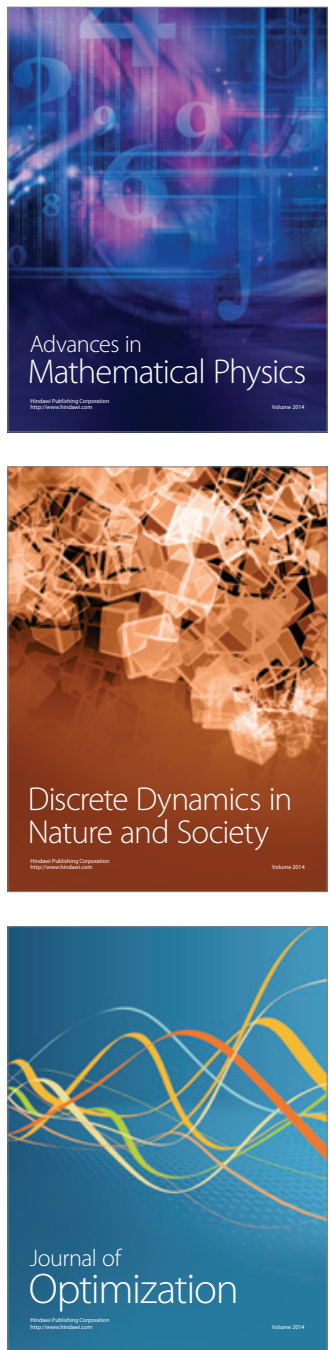